\title{
Sleep Quality in COPD Patients; Incidence and Predictors of Poor Quality
}

\author{
MOHAMMAD T. ABD EL-FATTAH, M.D.*; ALI O. ABD EL-AZIZ, M.D.*; \\ ELHAM A. ABD EL-GAHNY, M.D.* and MAHMOUD H.S. KHEDR, M.D.** \\ The Departments of Chest Diseases* and Internal Medicine**, Faculty of Medicine, Minia University, Egypt
}

\begin{abstract}
Objectives: Evaluation of sleep quality in COPD and relationship of PSQI (Pittsburgh Sleep Quality Index) score with health related quality of life, depression, anxiety and severity of airflow obstruction.
\end{abstract}

Patients and Methods: A prospective study of 124 COPD patients, 42 adult control. All completed PFT, ABG, routine investigation. All were age and gender matched. Quality of sleep measured by Pittsburgh Sleep Quality Index (PSQI). Health related quality of life was measured by diseasespecific (St. George's Respiratory) questionnaires. Anxiety, depression assessed by Hamilton scale and Beck's depression inventory.

Results: $53.2 \%$ of COPD patients had poor sleep quality, $50 \%$ had high risk of OSA with statistically significant difference regarding smoking index, spirometric parameters, 6-min walk test, Berlin questionnaire, PSQI, ESS, BDI and HAMA. COPD poor sleep quality had statistically higher, number of exacerbations, total SGRQ (St.George respiratory questionnaire), ESS (Epworth sleepiness scale), BDI, HAM-A. COPD patients with high risk of OSA had statistically significant number of exacerbations, shorter 6-min walk test and higher total SGRQ, ESS, PSQI, BDI and HAM-A. No relation between disease severity and sleep disturbance, health related quality of life. PSQI was correlated positively with COPD duration, number of exacerbation, PCO2, HAM-A (Hamilton Anxiety Rating Scale), BDI (Beck's Depression Inventory) and SGRQ. PSQI was correlated negatively with FEV 1, FVC\%, FEF25-75\%, use of (long acting muscarinic antagonists).

Conclusion: COPD is associated with poor sleep quality and high risk of OSA. Strong association between poor sleep quality and physical limitation, anxiety, depression and poor health related quality of life.

Key Words: COPD - Sleep quality - OSA - Health related quality of life - Depression - Anxiety.

\section{Introduction}

COPD patients are often associated with many extra pulmonary comorbidities and these comor-

Correspondence to: Dr. Mohammad T. Abd El-Fattah, The Department of Chest Diseases, Faculty of Medicine, Minia University, Egypt bidities contribute to the severity of the disease in selected patients [1]. Poor quality of sleep pattern together with other disturbances in sleep is common in patients with COPD [2-4]. There are significant differences between the sleep disorders in general population and disorders found in COPD patients [5].

In patients with stable COPD sleep quality is one of important indicators of quality of life $[2,3]$ The mechanisms responsible for poor sleep quality in COPD are currently not well known. Many mechanisms may be included as; cough or dyspnea [6], nocturnal oxygen desaturation [7], hypercapnia [8] or daytime hypoxemia. A recent study showed that; Melatonin might have a positive effect on sleep quality in patients with COPD [2]. Anxiety and depression have been associated with poor sleep quality [9]. Health Related Quality of Life (HrQOL) in COPD has been influenced by poor sleep quality [10]. This study was performed to evaluate subjective assessment of sleep quality in clinically stable COPD patients using Pittsburg questionnaire and to assess the relationship of PSQI score with health related quality of life using SGRQ, depression using Beck score, anxiety using Hamilton score and severity of airflow obstruction.

\section{Patients and Methods}

The present study was a prospective case control study that was conducted in the Chest Department,

\footnotetext{
Abbreviations:

PSQI : Pittsburgh Sleep Quality Index.

ESS : Epworth Sleepiness Scale.

SGRQ : St. George Respiratory Questionnaire.

HrQOL : Health Related Quality of Life.

BDI : Beck's Depression Inventory.

HAM-A : Hamilton Anxiety Rating Scale.

LAMA : Long Acting Muscarinic Antagonist.
} 
between June 2015 and September 2016. The study protocol was approved by the local Research Ethics Committee. The study included 124 consecutive patients with clinical and functional diagnosis of COPD and 42 adult healthy control subjects.

Data collected from all participants are:Demographic data: Age, sex, marital state, education state, occupation, smoking history, duration of COPD and history of comorbidities. Detailed general and local chest examination. Laboratory investigations including Complete Blood Count (CBC), renal and liver function tests, C-Reactive Protein (CRP) and Erythrocyte Sedimentation Rate (ESR). Arterial Blood Gases (ABGs). Pre and postbronchodilator spirometry. Sleep quality questionnaires: Pittsburgh Sleep Quality Index (PSQI). Other sleep related questionnaires including Berlin questionnaire and Epworth Sleepiness Scale (ESS). Health related quality of life questionnaire: Saint George respiratory questionnaire. Anxiety and depression questionnaire: Hamilton score and Beck's Depression Inventory (BDI) questionnaire.

COPD and its severity were defined according to GOLD guideline. COPD was diagnosed by the presence of chronic symptoms (chronic productive cough and dyspnea) and post-bronchodilator $\mathrm{FEV}_{1} /$ FVC < 70. COPD severity was defined as mild when post-bronchodilator FEV 1 from 50-79, mild when post-bronchodilator $\mathrm{FEV}_{1} \geq 80 \%$ predicted, moderate when post-bronchodilator FEV ${ }_{1}$ from $50-79 \%$ predicted, severe when post-bronchodilator $\mathrm{FEV}_{1}$ from 30-49\% predicted, very severe when post-bronchodilator FEV $1<30 \%$ predicted [1] Spirometry was performed by using spirometer (Lab Digital Spirometer 762600, Sensor medics). Grading of dyspnea was based on modified Medical Research Council (mMRC) dyspnea scale [11] Exercise performance was assessed using the Six Minute Walk Test [12]. The primary outcome was distance walked in 6 minutes.

Pittsburgh Sleep Quality Index (PSQI) is a 19item self-rating scale designed to measure the quality of sleep during the previous month using seven components of sleep i.e., sleep quality, sleep latency, sleep duration, sleep efficiency and sleep disturbance, use of sleep medications and daytime dysfunction [13]. The scale yields a total score that ranges from 0 to 21, with higher scores indicating more difficulties with sleep. A global score greater than 5 indicates a poor sleeper.

Berlin questionnaire was utilized for evaluation of sleep apnea. It contains 10 questions about risk factors of sleep apnea such as snoring, daytime sleepiness and fatigue, obesity, and hypertension. If the individual scores positive in at least two of the three categories, he/she are at high risk of sleep apnea [14]

Epworth Sleepiness Scale (ESS) questionnaire was employed for analysis of daytime sleepiness. It comprises 8 questions that depict situations in which the individual may become sleepy reluctantly. Each question takes 0 to 3 scores. If the patient's score is higher than 10 , he/she have more than usual daytime sleepiness [15]

Saint George respiratory questionnaire was used for assessment of quality of life of the patients. It contains 76 items about symptoms, impact, and activity of the disease, which provide total score according to index of effect of any subscore, from 0 to 100 for individual subscores and totally. Component scores measuring symptoms (Symptoms), impacts on daily life (Impacts), disturbance to daily activities (Activity), and an overall (Total) score are normally calculated. Higher score means lower quality of life in those subscores. It has been used in many diseases included lung disease such as asthma and COPD. Content of its questions is simple and easily understood by patients [16]

Anxiety was assessed by Hamilton Anxiety $(H A M-A):$ It is a 14 -items anxiety self-test, which gives a score on an anxiety scale [17]. Each item is scored on a scale of 0 (not present) to 4 (severe), with a total score ranges from 0-56. A total score of 18 or more means anxiety, 18-24: Mild anxiety, 25-29: Moderate anxiety, 30 and above: Severe anxiety.

Depression was assessed by Beck's Depression Inventory (BDI): The Beck Depression Inventory, 2nd edition (BDI; Beck, Steer et al., 1996), a 21item self-report measure of depression, was used to assess severity of depression. The BDI possesses strong internal consistency, factorial and convergent validity, and test-retest stability [18], and it has been validated for use with medical patients [19] Total scores ranging from 0 to 13 are indicative of minimal depression, 14-19 of mild depression, 2028 of moderate depression, and 29-63 of severe depression.

\section{Statistical analysis:}

Statistical analysis was performed using SPSS software Version (12.0; SPSS Inc., Chicago). Results are expressed as the mean and Standard Deviation (SD) for continuous variables and as percentages for categorical variables. Differences in continuous variables were assessed by student's $t$ - 
test and ANOVA. Chi-square test was used to determine the association between categorical variables. Correlation between PSQI scores and other variables were assessed by the Spearman rank correlation coefficient $(r)$. A $p$-value of less than 0.05 was considered as statistically significant.

\section{Results}

Table (1) demonstrates the demographic and characteristic data in COPD patients and control healthy subjects. The mean age of the whole subjects included in the study was ranged from 44 to 83 years with a mean of $61.2 \pm 8.1$ years. Males represented $75 \%$ of patients in COPD patients and $64.3 \%$ of control subjects. Both groups are matched as regard age, sex, BMI and education state. 53.2\% of the 124 COPD patients had poor sleep quality (indicated by high PSQI $>5$ ) and 50\% of them had high risk of OSA (indicated by Berlin questionnaire positive in at least 2 of the 3 categories). There was statistically significant difference between both groups regarding smoking index, spirometric parameters, 6-min walk test, Berlin questionnaire, PSQT, ESS, BDI and HAM-A.

Table (1): Demographic and spirometric data of studied subjects.

\begin{tabular}{|c|c|c|c|}
\hline & $\begin{array}{c}\text { COPD } \\
\text { patients } \\
(n=124)\end{array}$ & $\begin{array}{l}\text { Control } \\
\text { healthy } \\
(\mathrm{N}=42)\end{array}$ & $\begin{array}{c}p- \\
\text { value }\end{array}$ \\
\hline Age. & $61.9 \pm 9.1$ & $59.2 \pm 3.8$ & 0.07 \\
\hline \multicolumn{4}{|l|}{ Sex: } \\
\hline Male & $93(75 \%)$ & $27(64.3 \%)$ & \multirow[t]{2}{*}{0.23} \\
\hline Female & $31(25 \%)$ & $15(35.7 \%)$ & \\
\hline BMI $\left(\mathrm{kg} / \mathrm{m}^{2}\right)$ & $24.3 \pm 4.5$ & $24.4 \pm 5.8$ & 0.94 \\
\hline Smoking index (pack/year) & $30.7 \pm 23.7$ & $12.5 \pm 1.9$ & 0.0001 \\
\hline Pre-FEV1 (\% pred) & $33.7 \pm 12.2$ & $92.7 \pm 7.5$ & 0.0001 \\
\hline Pre-FVC (\% pred) & $47.9 \pm 13.6$ & $88.5 \pm 6.0$ & 0.0001 \\
\hline Pre-FEF25-75 (\% pred) & $17.0 \pm 9.8$ & $77.1 \pm 10.1$ & 0.0001 \\
\hline Pre-FEV1/FVC $\%$ & $51.8 \pm 9.5$ & $81.6 \pm 5.5$ & 0.0001 \\
\hline 6-min walk distance (meter) & $174.4 \pm 77.9$ & $370.7 \pm 35.9$ & 0.0001 \\
\hline \multicolumn{4}{|l|}{ Berlin questionnaire: } \\
\hline 0 & $35(28.2 \%)$ & $15(35.7 \%)$ & \multirow[t]{4}{*}{0.0001} \\
\hline 1 & $27(21.8 \%)$ & $18(42.9 \%)$ & \\
\hline 2 & $46(37.1 \%)$ & $7 \quad(16.7 \%)$ & \\
\hline 3 & $16(12.9 \%)$ & $2(4.8 \%)$ & \\
\hline \multicolumn{4}{|l|}{ PSQI: } \\
\hline Total & $7.8 \pm 4.9$ & $3.1 \pm 1.5$ & \multirow[t]{3}{*}{0.001} \\
\hline$\leq 5$ & $58(46.8 \%)$ & $32(76.2 \%)$ & \\
\hline$>5$ & $66(53.2 \%)$ & $10(23.8 \%)$ & \\
\hline \multicolumn{4}{|l|}{ ESS: } \\
\hline Total & $7.9 \pm 4.9$ & $2.5 \pm 2.1$ & \multirow[t]{3}{*}{0.001} \\
\hline$\leq 10$ & $93(75 \%)$ & $35(83.3 \%)$ & \\
\hline$>10$ & $31(25 \%)$ & $7 \quad(16.7 \%)$ & \\
\hline BDI & $16.5 \pm 6.6$ & $3.07 \pm 0.3$ & 0.001 \\
\hline HAM-A & $13.0 \pm 5.2$ & $2.7 \pm 1.2$ & 0.001 \\
\hline
\end{tabular}

$*$ : Data presented as mean $\pm \mathrm{SD}$

**: Data presented as number (percentage).
Table (2) demonstrates other characteristics of COPD patients. The most frequent comorbid disorder associated with COPD was cardiac diseases followed by hypertension and then diabetes mellitus.

Table (2): Other characteristics of COPD patients.

\begin{tabular}{|c|c|}
\hline & COPD patients $(n=124)$ \\
\hline COPD duration & $10.9 \pm 7.1 *$ \\
\hline Number of exacerbations & $3.3 \pm 2.2$ \\
\hline Post-FEV1 (\% pred) & $37.8 \pm 12.8$ \\
\hline Post-FVC (\% pred) & $52.5 \pm 13.1$ \\
\hline Post-FEV1/FVC (\%) & $53.6 \pm 9.9$ \\
\hline Post-FEF25-75 (\% pred) & $20.6 \pm 13.7$ \\
\hline $\mathrm{pH}$ & $7.36 \pm 0.05$ \\
\hline $\mathrm{PaCO} 2 \mathrm{mmHg}$ & $51.7 \pm 12.8$ \\
\hline $\mathrm{HCO} 3$ & $28.4 \pm 4.7$ \\
\hline $\mathrm{PaO} 2 \mathrm{mmHg}$ & $50.2 \pm 13.9$ \\
\hline $\mathrm{SaO} 2 \%$ & $80.3 \pm 14.9$ \\
\hline $\begin{array}{l}\text { Gold severity: } \\
\text { Moderate } \\
\text { Severe } \\
\text { Very severe }\end{array}$ & $\begin{array}{l}24(18.5 \%)^{* *} \\
56(46 \%) \\
44(35.5 \%)\end{array}$ \\
\hline $\begin{array}{l}\text { The presence of comorbid disea } \\
\text { Cardiac disease } \\
\text { Hypertension } \\
\text { Diabetes mellitus } \\
\text { Liver disease } \\
\text { Renal disease } \\
\text { Neurological disease }\end{array}$ & $\begin{array}{ll}44 & (35.5 \%) \\
41 & (33.1 \%) \\
18 & (14.5 \%) \\
2 & (1.6 \%) \\
1 & (0.8 \%) \\
1 & (0.8 \%)\end{array}$ \\
\hline $\begin{array}{l}S G R Q: \\
\text { Total } \\
\text { Symptoms } \\
\text { Activity } \\
\text { Impacts }\end{array}$ & $\begin{array}{l}68.2 \pm 15.6 \\
74.9 \pm 15.1 \\
69.7 \pm 17.3 \\
65.3 \pm 18.7\end{array}$ \\
\hline $\begin{array}{l}\text { Inhaled medication use: } \\
\text { Short acting B2-agonsits } \\
\text { Short acting anti-muscarinic } \\
\text { Long acting B2-agonsits } \\
\text { Long acting anti-muscarinic } \\
\text { Inhaled corticosteroids }\end{array}$ & $\begin{array}{ll}65 & (52.5 \%) \\
1 & (0.8 \%) \\
103 & (83.1 \%) \\
60 & (48.4 \%) \\
105 & (84.7 \%)\end{array}$ \\
\hline
\end{tabular}

Table (3) demonstrates comparison between COPD patients with poor sleep quality and those with good sleep quality. COPD patients with poor sleep quality (indicated by high PSQI $>5$ ) had statistically significant higher number of exacerbations, COPD duration, cough symptomatology and use of LAMA. In COPD patients with poor sleep quality FEV 1, FVC\% and PEF 25-57\% and $\mathrm{pH}$ were significantly lower and PCO 2 was significantly higher. As regard spirometric parameters, there was statistically significant difference between both groups as regard FEV 1, FVC\% and PEF25$57 \%$, that was significantly lower in COPD patients with poor sleep quality. COPD patients with poor sleep quality had statistically significant lower $\mathrm{pH}$ and higher $\mathrm{PaCO}$ 2. COPD patients with poor sleep quality had statistically significant higher total 
SGRQ, ESS, BDI and HAM-A. There was no statistically significant difference between both groups regarding age, BMI, smoking index, $\mathrm{PaO}_{2}$, $\mathrm{SaO}_{2}$ and $\mathrm{mMRC}$.

Table (3): Comparison between COPD patients with poor sleep quality and those with good sleep quality (indicated by high PSQI $>5$ ).

\begin{tabular}{llll}
\hline & $\begin{array}{c}\text { Patients good } \\
\text { sleep quality } \\
(\mathrm{n}=58)\end{array}$ & $\begin{array}{c}\text { Patients poor } \\
\text { sleep quality } \\
(\mathrm{n}=66)\end{array}$ & $\begin{array}{c}p \text { - } \\
\text { value }\end{array}$ \\
\hline Age (year) & $61.5 \pm 9.0 *$ & $62.2 \pm 9.2$ & 0.69 \\
Smoking index pack/year & $30.3 \pm 22.4$ & $31.1 \pm 24.9$ & 0.83 \\
BMI (kg/m ${ }^{2}$ ) & $23.5 \pm 3.9$ & $25.0 \pm 4.9$ & 0.07 \\
Number of exacerbations/year & $2.8 \pm 1.6$ & $3.8 \pm 2.6$ & 0.02 \\
COPD duration (year) & $9.0 \pm 5.4$ & $12.5 \pm 8.0$ & 0.03 \\
mMRC & $3.4 \pm 0.7$ & $3.0 \pm 0.6$ & 0.41 \\
Cough & $42(72.4 \%)$ & $58(87.9 \%)$ & 0.04 \\
Wheeze & $44(75.9 \%)$ & $57(86.4 \%)$ & 0.28 \\
History of cardiac diseases & $38(65.5 \%)$ & $42(63.6 \%)$ & 0.04 \\
History of hypertension & $22(72.4 \%)$ & $19(28.8 \%)$ & 0.19 \\
History of diabetes mellitus & $6(10.3 \%)$ & $12(18.2 \%)$ & 0.16 \\
Use of LABA & $50(86.2 \%)$ & $53(80.3 \%)$ & 0.26 \\
Use of LAMA & $33(56.9 \%)$ & $27(40.9 \%)$ & 0.049 \\
Post-FEV1 (\% pred) & $40.2 \pm 13.2$ & $35.6 \pm 12.1$ & 0.04 \\
Post-FVC $(\%$ pred) & $54.9 \pm 13.4$ & $50.3 \pm 12.5$ & 0.04 \\
Post-FEV1/FVC (\%) & $53.8 \pm 10.9$ & $53.4 \pm 9.0$ & 0.85 \\
Post-FEF25-75 (\% pred) & $25.0 \pm 17.2$ & $16.7 \pm 8.2$ & 0.001 \\
pH & $7.37 \pm 0.04$ & $7.35 \pm 0.05$ & 0.02 \\
PaCO2 mmHg & $48.5 \pm 10.9$ & $54.5 \pm 13.7$ & 0.009 \\
HCO3 & $27.5 \pm 4.4$ & $29.2 \pm 4.9$ & 0.06 \\
PaO2 mmHg & $51.5 \pm 13.7$ & $49.0 \pm 14.2$ & 0.32 \\
SaO2\% & $81.9 \pm 14.8$ & $78.9 \pm 14.9$ & 0.25 \\
6-min walk distance (meter) & $191.2 \pm 75.7$ & $159.5 \pm 77.4$ & 0.02 \\
\hline
\end{tabular}

* : Data presented as mean $\pm \mathrm{SD}$

**: Data presented as number (percentage).

The proportions of patients with poor sleep quality that reported high risk of OSA (74.1\%) was significantly higher than patients with low risk of OSA (28.8\%). Also, the proportion of patients with poor sleep quality that had low ESS (47\%) was significantly higher than patients with high ESS (0\%) Table (4).

Table (4): Comparison between COPD patients with poor sleep quality and those with good sleep quality (indicated by high PSQI $>5$ ).

\begin{tabular}{llll}
\hline & $\begin{array}{c}\text { Patients with } \\
\text { poor sleep } \\
\text { quality (n=66) }\end{array}$ & $\begin{array}{c}\text { Patients with } \\
\text { good sleep } \\
\text { quality (n=58) }\end{array}$ & $\begin{array}{c}p \text { - } \\
\text { value }\end{array}$ \\
\hline SGRQ: & $62.7 \pm 15.5$ & $73.3 \pm 14.1$ & 0.002 \\
$\quad$ Total & $71.3 \pm 16.7$ & $78.1 \pm 12.9$ & 0.04 \\
$\quad$ Symptoms & $64.5 \pm 16.1$ & $74.4 \pm 17.2$ & 0.01 \\
Activity & $5809 \pm 19.3$ & $71.2 \pm 16.3$ & 0.003 \\
Impacts & $3.3 \pm 1.4$ & $11.8 \pm 3.2$ & 0.0001 \\
PSQI & $4.5 \pm 2.4$ & $10.1 \pm 4.6$ & 0.0001 \\
ESS & $11.4 \pm 5.1$ & $14.5 \pm 4.9$ & 0.001 \\
HAM-A & $13.7 \pm 6.1$ & $18.9 \pm 6.0$ & 0.0001 \\
BDI & & & \\
Berlin questionnaire: & $15(25.9 \%)$ & $47(71.2 \%)$ & 0.0001 \\
$\quad$ Category 2 and 3 & $43(74.1 \%)^{*}$ & $19(28.8 \%)$ & \\
$\quad$ Category 1 & & & \\
ESS: & $35(53.0 \%)$ & $58(98.4 \%)$ & 0.0001 \\
$\quad$ Low ESS $(\leq 10)$ & $31(47.0 \%)$ & $0(0 \%)$ & \\
$\quad$ High ESS $(>10)$ & &
\end{tabular}

*: Data data presented as number (percentage).
Table (5) demonstrates comparison between COPD patients with high risk of OSA and those with low risk of OSA. COPD patients with high risk of OSA (indicated by Berlin questionnaire positive in at least 2 of the 3 categories) had statistically significant higher number of exacerbations and lower FEV $1 \%$, PEF 25-57\% than those with good sleep quality. COPD patients with poor sleep quality had statistically significant shorter 6-min walk distance and higher total SGRQ, ESS, PSQI, BDI and HAM-A.

Table (5): Comparison between COPD patients with high risk of OSA (those with Berlin questionnaire positive in at least 2 of the 3 categories) and those with low risk of OSA (those with Berlin questionnaire positive in only one of the 3 categories).

\begin{tabular}{llll}
\hline & $\begin{array}{c}\text { Patients with } \\
\text { low risk of } \\
\text { OSA (n=62) }\end{array}$ & $\begin{array}{c}\text { Patients with } \\
\text { high risk of } \\
\text { OSA }(\mathrm{n}=62)\end{array}$ & $\begin{array}{c}p \text { - } \\
\text { value }\end{array}$ \\
\hline Age (year) & $61.1 \pm 9.3 *$ & $62.6 \pm 8.9$ & 0.36 \\
BMI (kg/m ${ }^{2}$ ) & $23.9 \pm 3.1$ & $24.6 \pm 5.6$ & 0.43 \\
Smoking index pack/year & $28.7 \pm 22.7$ & $32.7 \pm 24.7$ & 0.34 \\
Number of exacerbations/year & $2.7 \pm 1.4$ & $4.0 \pm 2.7$ & 0.001 \\
Cough & $59(80.8 \%) * *$ & $39(74.5 \%)$ & 0.37 \\
COPD duration (year) & $9.9 \pm 4.4$ & $11.4 \pm 8.1$ & 0.36 \\
mMRC & $3.5 \pm 0.6$ & $3.4 \pm 0.7$ & 0.61 \\
Use of LABA & $55(88.7 \%)$ & $48(77.4 \%)$ & 0.07 \\
Use of LAMA & $37(59.7 \%)$ & $23(37.1 \%)$ & 0.01 \\
Post-FEV1 (\% pred) & $30.4 \pm 13.0$ & $35.1 \pm 12.1$ & 0.02 \\
Post-FVC (\% pred) & $54.4 \pm 13.3$ & $50.5 \pm 12.4$ & 0.09 \\
Post-FEV1/FVC (\%) & $54.5 \pm 10.4$ & $52.6 \pm 9.4$ & 0.28 \\
Post-FEF25-75 (\% pred) & $24.1 \pm 13.9$ & $17.1 \pm 12.7$ & 0.005 \\
pH & $7.37 \pm 0.04$ & $7.35 \pm 0.05$ & 0.08 \\
PaCO2 mmHg & $49.7 \pm 15.1$ & $53.7 \pm 14.1$ & 0.08 \\
HCO3 & $27.8 \pm 4.4$ & $29.1 \pm 4.9$ & 0.13 \\
PaO2 mmHg & $50.9 \pm 13.9$ & $49.6 \pm 14.1$ & 0.60 \\
SaO2\% & $82.0 \pm 14.1$ & $78.6 \pm 15.6$ & 0.20 \\
6-min walk distance (meter) & $195.5 \pm 79.3$ & $153.2 \pm 71.2$ & 0.002 \\
\hline * : Data presented as mean \pm SD. & & \\
**: Data presented as number (percentage). & & \\
\end{tabular}

Table (6): Comparison between COPD patients with high risk of OSA (those with Berlin questionnaire positive in at least 2 of the 3 categories) and those with low risk of OSA (those with Berlin questionnaire positive in only one of the 3 categories).

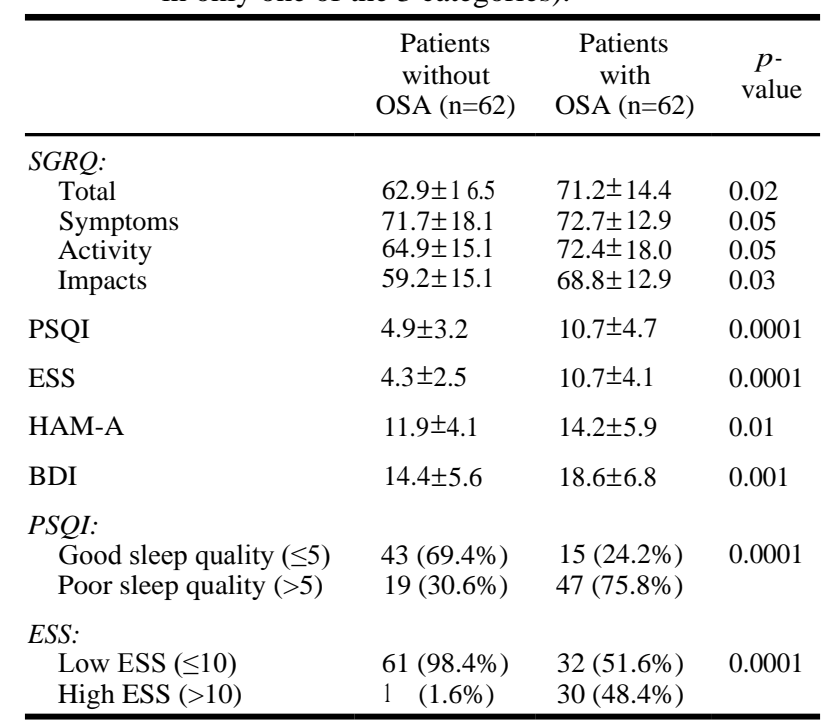


The proportion of patients with high risk of OSA that reported poor quality of sleep was significantly higher than patients with low risk of OSA Table (6).

Table (7) demonstrates correlation between PSQI and other patient's characteristics. PSQI correlated positively with COPD duration, number of exacerbation, PCO 2, HAM-A, BDI and SGRQ. PSQI correlated negatively with FEV $1 \%$, FVC\%, FEF25-75\%, use of LAMA and 6-min walk distance.

Table (7): Correlation between PSQI and other patient's characteristics.

\begin{tabular}{lcc}
\hline & \multicolumn{2}{c}{ PSQI } \\
\cline { 2 - 3 } & $r$ & $p$ \\
\hline Duration of COPD & 257 & $0.02^{* *}$ \\
Number of exacerbation & 339 & $0.0001^{* *}$ \\
Use of LAMA & -306 & $0.001 * *$ \\
FEV1 (\% pred.) & -197 & $0.03^{*}$ \\
FVC (\% pred.) & -188 & $0.04 *$ \\
FEF25-75 (\% pred.) & -344 & $0.0001^{* *}$ \\
PCO2 mmHg & 251 & $0.049 * *$ \\
HAM-A & 287 & $0.001^{* * *}$ \\
BDI & 401 & $0.0001^{* *}$ \\
6-min walk distance (meter) & -251 & $0.049^{* *}$ \\
SGRQ: & & \\
$\quad$ Total & 367 & $0.001 * *$ \\
Symptoms & 250 & $0.05 * *$ \\
Activity & 312 & $0.005^{* *}$ \\
Impacts & 351 & $0.001^{* *}$ \\
\hline$* *$ Correlation is significant at the 0.01 level (2-tailed). \\
* Correlation is significan. & & \\
\hline
\end{tabular}

\section{Discussion}

Sleep disturbance in COPD patients are frequent and it leads to nonspecific daytime chronic fatigue, lethargy and overall impairment in quality of life. Thus, overall sense of well-being can be improved by accurate diagnosis and management of sleep disorders in COPD patients [2].

The present study found that $53.2 \%$ of COPD patients had poor sleep quality (indicated by PSQI $>5$ ) that was significantly higher than those in control group without COPD. This is consistent with previous studies [2,3]. Chang et al., [20] reported similar results. In a study of 59 patients with moderate to severe COPD, Lewis et al., [21] showed that Poor Sleep Quality (PSQI >5) in 61\% of COPD patients regardless of their advanced age. Other two studies showed higher values (78\% and $78.1 \%$ ) $[22,23]$. However, the patients numbers in those studies was small (28 and 64 patients respectively).
Sleep disorders in COPD patients appear to have multifactorial and complex mechanisms. Many factors appear to be involved including; physiological changes associated with sleep, hypoxemia, hypercapnia. In addition, inflammation, medications used for COPD treatment, and/or nicotine use can be included. Other associated comorbidities and primary sleep disorders are included in the mechanism of sleep disorders in COPD patients; [24].

Negative correlation was found between PSQI value and FEV 1, FVC and FEF25-75\%. In consistent to our results, In et al., [25] found negative correlation between PSQI and FEV $1 \%$ and FVC\%. Also Sajal et al., [26] reported that FVC, and FEV 1 were considered as independent variables to predict global PSQI scores. As regard relationship, either between the degree of airflow obstruction (FEV $\left.{ }_{1} \%\right)$ and sleep quality (PSQI) or between GOLD class and sleep quality Scharf et al., found statistically insignificant difference [3]. In contrast to the previous results $\mathrm{PaCO} 2$ was a significantly higher in patients with poor sleep quality ( $p=0.009)$. These results in agreement with a previous study [27] Hypercarpia has been shown to increase sympathetic activity in some studies $[28,29] .87 .9 \%$ of patients with poor sleep quality have cough which is significantly higher than in patients with good sleep quality $(p=0.04)$. Other studies results come in agreement with our study, which showed that associated cough and sputum production appear to be important predictors of sleep disturbances $[6,30]$. The present study showed no association between sleep quality with age that is consistent with previous studies $[3,6]$. There was also no association between sleep qualities with smoking. This is in agreement with a previous study [31] However, a recent study found that smoking was associated with sleep initiation and sleep fragmentation [32]. Medications used for treatment of COPD e.g., salbutamol, theophylline, steroid can affect the sleep quality. However, previous studies did not demonstrate any correlation between sleep quality and the use of such treatments in COPD $[33,34]$. In our study, the use of inhaled long acting muscarinic antagonists was associated with good sleep quality in the COPD patients. This is consistent with two previous studies $[4,34]$. This could be due to the better control of symptoms with the addition of inhaled LAMA to the usual treatment of COPD patients.

In the present study poor sleep quality was significantly associated with increased number of acute exacerbation $(p=0.02)$. This comes in agreement with other studies $[\mathbf{6 , 3 5 , 3 6 ]}$. Whether poor 
sleep quality precipitate AECOPD or AECOPD be a contributing factor to poor sleep quality in COPD is difficult to determine from our results. Sleep disorders is a documented risk factor for some comorbidities such as; glucose intolerance, hypertension, cardiovascular disease, and can increase airflow obstruction in COPD and hence precipitating exacerbations [25]. On the other hand, AECOPD could worsen sleep quality through increased symptomatology, aggravating hypoxemia and hypercarpia, increased level of systemic inflammation, and increased medication used. Poor sleep quality and AECOP are considered common pathophysiological mechanisms including; higher levels of proinflammatory cytokines, high burden of airway pathogens, and undiagnosed sleep disordered breathing [25]

The present study found that $50 \%$ of COPD patients had increased risk of OSA (indicated by categories 2 or 3 Berlin questionnaire), compared to $21.4 \%$ in normal subjects without COPD. In consistent with our study, Zohal et al., [35] reported that about half of 139 COPD patients had increased risk of OSA. Bellia et al., [37] reported one or more sleep disturbances were reported by $60.6 \%$ (445 out of 734 patients with chronic airway diseases) vs. $56.4 \%$ (697 out of 1237 controls normal subjects). Another study found a prevalence of OSA in moderate-to-severe COPD patients of $66 \%$ [38] The higher concurrence rate of OSA and COPD can be attributed to several factors other than only chance. The chronic oral steroids used by some patients with severe COPD may cause central obesity and deposition of fat in the neck, which in turn increase the risk of OSA. Right ventricular dysfunction and right heart failure that can occur as a complication of COPD may cause edema in the pharyngeal soft tissues, which can predispose to OSA. COPD is a cause of limited exercise capacity and hence contribute to obesity, which is a risk factor for OSA. The generalized muscle weakness associated with COPD could promote also upper airway collapsibility [25]. In contrast to our study, some studies reported no increase in the prevalence of OSA among COPD patients comparing to the general population $[39,40]$. The controversy regarding whether sleep apnea prevalence is higher in COPD as compared to matched individuals without COPD could be attributed to the heterogeneity of the studied patients in different studies, the different diagnostic techniques used, and to the different associated risk factors in the cohort being studied.

In the present study, only $25 \%$ of COPD patients had excessive sleepiness as assessed by the ESS score. Although higher percentage $(53.2 \%)$ had poor sleep quality as assessed by the PSQI. This is consistent with Scharf et al., study [3] . Insomnia without excessive sleepiness was an important sleep complaint reported by our patients. The causes for the discrepancy between the high prevalence of poor sleep quality and the lack of excessive sleepiness are not obvious. Medication use, sympathetic hyperstimulation, or anxiety all can cause a hyper alert state, which in turn decreasing the extent of excessive sleepiness [3]. Other possible causes might include cultural background of some patients and some patients do not like to admit that; they are sleepy.

We reported a mean SGRQ score of 68.2. Scharf et al., [3] reported a mean SGRQ score of 57.0. While, other studies have reported lower mean SGRQ scores [2,4]. In our study, mean SGRQ score (total, symptom, impact, activity and impact) are significantly higher in COPD patients with poor sleep quality. In consistent to our results, PSQI Index was found to be an independent predictor of quality of life in COPD patients in Scharf et al., study [3]. In our study, PSQI was found to be correlated with SGRQ (total, symptoms, activity and impact). This means that sleep quality predicts overall and disease-specific health related quality of life. These results are in agreement with previous results [2-4]

In the present study, we found strong correlation between depression and anxiety scores and sleep indices (PSQI, ESS). This finding confirms the established relationship between sleep disturbances in depression and anxiety $[\mathbf{6 , 4 1}, \mathbf{4 2}]$. Depressive symptoms were found to have strong association with subjective sleep quality and moderately associated with objective sleep quality [43]. Tsuno et al., [44] reported that $90 \%$ of patients with depression are troubled with poor sleep quality. They also found that in $40 \%$ of cases sleep complaints occurs before an episode of depression. Suh et al., [45] found that COPD patients with anxiety have significantly higher PSQI than patients without anxiety (12.0 versus 6.9 respectively).

\section{Conclusion:}

Our study concluded that COPD patients have poor sleep quality and high risk of OSA. There is strong association between poor sleep quality and physical limitation, COPD exacerbation, anxiety, depression and poor health related quality of life. The main limitations of this study are the lack of objective data as those obtained from polysomnography. 


\section{References}

1- Global initiative for the diagnosis, management and prevention of chronic obstructive pulmonary disease. Updated, 2016.

2- NUNES D.M., MOTA R.M., De PONTES NETO O.L., PEREIRA E.D., De BRUIN V.M. and De BRUIN P.F.: Impaired sleep reduces quality of life in chronic obstructive pulmonary disease. Lung, 187 (3): 159-63, 2009.

3- SCHARF S.M., MAIMON N., SIMON-TUVAL T., BERNHARD-SCHARF B.J., REUVENI H. and TARASIUK A.: Sleep quality predicts quality of life in chronic obstructive pulmonary disease. Int. J. Chron. Obstruct. Pulmon. Dis., 6: 1-12, 2011.

4- HYNNINEN M.J., PALLESEN S. and NORDHUS I.H.: Factors affecting health status in COPD patients with comorbid anxiety or depression. Int. J. Chron. Obstruct. Pulmon Dis., 2: 323-8, 2007.

5- VALIPOUR A., LAVIE P., LOTHALLER H., MIKULIC I. and BURGHUBER O.C.: Sleep profile and symptoms of sleep disorders in patients with stable mild to moderate chronic obstructive pulmonary disease. Sleep Med., 12 (4): 367-72, 2011.

6- OMACHI T.A., BLANC P.D., CLAMAN D.M., T CHEN H., YELIN E.H., JULIAN L., et al.: Disturbed sleep among COPD patients is longitudinally associated with mortality and adverse COPD outcomes. Sleep Med., 13: 476-83, 2012

7- CORMICK W., OLSON L.G., HENSLEY M.J. and SAUNDERS N.A.: Nocturnal hypoxaemia and quality of sleep in patients with chronic obstructive lung disease. Thorax, 41: 846-54, 1986.

8- HEDEMARK L.L. and KRONENBERG R.S.: Ventilatory and heart rate responses to hypoxia and hypercapnia during sleep in adults. J. Appl. Physiol. Respir. Environ. Exerc. Physiol., 53: 307-12, 1982.

9- MAYERS A.G., GRABAU E.A., CAMPBELL C. and BALDWIN D.S.: Subjective sleep, depression and anxiety: Inter-relationships in a non-clinical sample. Hum Psychopharmacol., 24: 495-501, 2009.

10- KRACHMAN S., MINAI M.A. and SCHARF S.M.: Sleep abnormalities and treatment in emphysema. Proc. Am. Thorac. Soc., 5: 536-42, 2008.

11- MAHLER D.A. and WELLS C.K.: Evaluation of clinical methods for rating dyspnea. Chest, 93 (3): 580-6, 1988.

12- FISHMAN A.P.: Pulmonary rehabilitation research. Am. J. Respir. Crit. Care Med. Mar., 149 (3 Pt 1): 825-33, 1994.

13- BUYSEE D.J., REYNODS C.F. 3rd, MONK T.H., BERMAN S.R. and KUPFER D.J.: The Pittsburgh Sleep Quality Index: A new instrument for psychiatric practice and research. Psychiatry Res., 28: 193-13, 1989.

14- NETZER N.C., STOOHS R.A., NETZER C.M., CLARK K. and STROHL K.P.: Using the Berlin Questionnaire to identify patients at risk for the sleep apnea syndrome. Annals of Internal Medicine, Vol. 131, No. 7, pp. 48591, 1999.

15- SADEGHNIIAT K.H., MONTAZERI A., KHAJEH A.M., MOLLER H.J., SARAEI1 M. and AMINIAN O.: Epworth sleepiness scale: Translation and validation study of the Iranian version. Sleep and Breathing, pp. 1-8, 2012.

16- MEGURO M., BARLEY E.A., SPENCER S. and JONES P.W.: Development and validation of an improved, COPDspecific version of the Saint George's Respiratory Questionnaire. Chest, 132: 456-63, 2007.

17- HAMILTON A.: Diagnosis and rating of anxiety, Br. J. Psychiatry, 3: 76-79, 1969.

18- BECK A.T., STEER R.A. and BROWN G.K.: Beck Depression Inventory-Second edition. Manual. San Antonio: Harcourt Brace \& Co.

19- ARNAU R.C., MEAGHER M.W., NORRIS M.P. and BRAMSON R.: Psychometric evaluation of the Beck Depression Inventory-II with primary care medical patients. Health Psychol., 20: 112-19.

20- CHANG C.H., CHUANG L.P., LIN S.W., et al.: Factors responsible for poor sleep quality in patients with chronic obstructive pulmonary disease. B.M.C. Pulmonary Medicine, 16: 118. Doi 10.1186/s12890-016-0281-6, 2016.

21- LEWIS C.A., FERGUSSON W., EATON T., ZENG I. and KOLBE J.: Isolated nocturnal desaturation in COPD: Prevalence and impact on quality of life and sleep. Thorax, 64: 133-8, 2009.

22- McDONNELL L.M., HOGG L., McDONNELL L. and WHITE P.: 'Pulmonary rehabilitation and sleep quality: A before and after controlled study of patients with chronic obstructive pulmonary disease' NPJ primary care respiratory medicine, Vol. 24, 14028.

23- PEDRAMRAZI S., KHEZRI Y., NEJATI S. and KAZEMNEJAD A.: Determining effect of controlled breathing on sleep quality in patient with chronic obstructive pulmonary disease. Nurs. Pract. Today, 2 (2): 69-75, 2015.

24- BUDHIRAJA R., SIDDIQI T.A. and QUAN S.F.: Sleep Disorders in Chronic Obstructive Pulmonary Disease: Etiology, Impact, and Management. Journal of Clinical Sleep Medicine, Vol. 11, No. 3, 2015.

25- IN E., TURGUT T. and ÖZDEMIR C.: Impact of Restless Legs Syndrome on the Sleep Quality in Chronic Obstructive Pulmonary Disease. Eurasian J. Pulmonol., 18: 1823, 2016.

26- SAJAL De: Subjective assessment of quality of sleep in chronic obstructive pulmonary disease patient and its relationship with associated depression. Lung India, Vol. 29, Issue 4, Oct.-Dec., 332-35. doi: 10.4103/0970-2113. 102808, 2012.

27- MEECHAM JONES D.J., PAUL E.A., JONES P.W. and WEDZICHA J.A.: Nasal pressure support ventilation plus oxygen compared with oxygen therapy alone in hypercapnic COPD. Am. J. Respir. Crit. Care Med., 152: 538-44, 1995.

28- OIKAWA S., HIRAKAWA H., KUSAKABE T., NAKASHIMA Y. and HAYASHIDA Y. Autonomic cardiovascular responses to hypercapnia in conscious rats: The roles of the chemo-and baroreceptors. Auton. Neurosci., 117: 105-14, 2005.

29- MORGAN B.J., CRABTREE D.C., PALTA M. and SKATRUD J.B.: Combined hypoxia and hypercapnia evokes long-lasting sympathetic activation in humans. J. Appl. Physiol., 79: 205-13, 1995. 
30- KIINK M.E., DODGE R. and QUAN S.F.: The relation of sleep complaints to respiratory symptoms in a general population. Chest, 105 (1): 151-4, 1994.

31- KARACAN I., THORBY J. and WILLIAMS R.: Sleep disturbance: A community survey. In: Guilleminault C., Lugaresi E., ed. Sleep/wake disorders: Natural history, epidemiology and longterm evolution. New York: Raven Press, 45-55, 1983.

32- WETTER D. and YOUNG T.: The relation between cigarette smoking and sleep disturbance. Prev. Med., 23: 32834, 1994.

33- McNICHOLAS W.T., CALVERLEY P.M., LEE A. and EDWARDS J.C.: Long-acting inhaled anticholinergic therapy improves sleeping oxygen saturation in COPD. Eur. Respir. J., 23 (6): 825-3 1, 2004.

34- MARTIN R.J., BARTELSON B.L., SMITH P., HUDGEL D.W., LEWIS D., POHL G., et al.: Effect of ipratropium bromide treatment on oxygen saturation and sleep quality in COPD. Chest, 115: 1338-45, 1999.

35- ZOHAL M.A., YAZDI Z., KAZEMIFAR A.M., PARISA MAHJOOB P. and MASOMEH ZIAEEHA M.: Sleep Quality and Quality of Life in COPD Patients with and without Suspected Obstructive Sleep Apnea. Hindawi Publishing Corporation Sleep Disorders. Volume 2014, Article ID 5083 72. doi.org/10.1155/2014/508372.

36- GEIGER-BROWN J., LINDBERG S., KRACHMAN S. McEVOY C.E., CRINER G.J., CONNETT J.E., et al.: "Self-reported sleep quality and acute exacerbations of chronic obstructive pulmonary disease," International Journal of Chronic Obstructive Pulmonary Disease, Vol. 10, pp. 389-97, 2015.

37- BELLIA V., CATALANO F., SCICHILONE N., et al.: Sleep disorders in the elderly with and without chronic airflow obstruction: The SARA Study. Sleep, Vol. 26, No. 3: 318-23, 2003.

38- SOLER X., GAIO E., POWELL F.L., RAMSDELL J.W.,
LOREDO J.S., MALHOTRA A., et al.: "High prevalence of obstructive sleep apnea in patients with moderate to severe chronic obstructive pulmonary disease," Annals of the American Thoracic Society, Vol. 12, No. 8, pp. 1219-25, 2015.

39- ZAMARRÓN C. 1., GARCÍA PAZ V., MORETE E. and DEL CAMPO MATÍAS F.: Association of chronic obstructive pulmonary disease and obstructive sleep apnea consequences. Int. J. Chron. Obstruct. Pulmon. Dis., Dec., 3 (4): 671-82, 2008.

40- CHAOUAT A., WEITZENBLUM E., KRIEGER J., SFORZA E., HAMMAD H., OSWALD M. and KESSLER R.: Prognostic value of lung function and pulmonary haemodynamics in OSA patients treated with CPAP. Eur. Respir. J., 13: 1091-6, 1999.

41- FOLEY D.J., MONJAN A.A., BROWN S.L., SIMONSICK E.M., WALLACE R.B. and BLAZER D.G.: Sleep complaints among elderly persons: An epidemiologic study of three communities. Sleep, 18: 425-32, 1995.

42- MAGGI S., LANGLOIS J.A., MINICUCI N., GRIGOLETTO F., PAVAN M., FOLEY D.J. and ENZI G.: Sleep complaints in community-dwelling older persons: Prevalence, associated factors, and reported causes. J. Am. Geriatr. Soc., 46: 161-8, 1998.

43- PAUDEL M.L., TAYLOR B.C., DIEM S.J., STONE K.L., ANCOLI-ISRAEL S., REDLINE S., et al.: Association between depressive symptoms and sleep disturbances among community-dwelling older men. J. Am. Geriatr. Soc., 56: 1228-35, 2008.

44- TSUNO N., BESSET A. and RITCHIE K.: Sleep and depression. J. Clin. Psychiatry., 66: 1254-69, 2005.

45- SUH S., ELLIS R.J., SOLLERS J.J. $3^{\text {rd }}$, THAYER J.F., YANG H.C. and EMERY C.F.: The effect of anxiety on heart rate variability, depression, and sleep in Chronic Obstructive Pulmonary Disease. Journal of Psychosomatic Research, 74: 407-13, 2013. 


\section{جودة النوم في مرضبى الإنسلداد الرئوى المزمن،

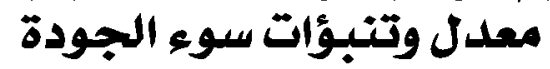

الآهداف: التقييم الشخصى لجودة النوم في مرضى الإنسداد الرئوى المزمن ذوى الحالة الإكلينيكية المستقرة لتحديد العلاقة بين معدل

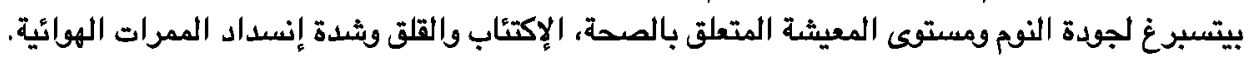

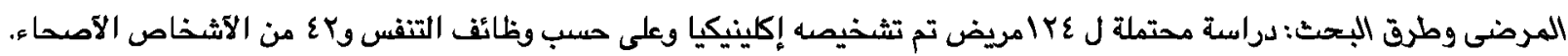

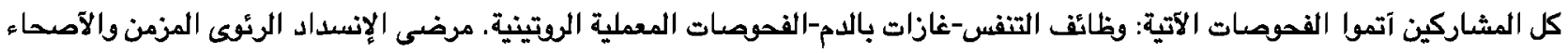

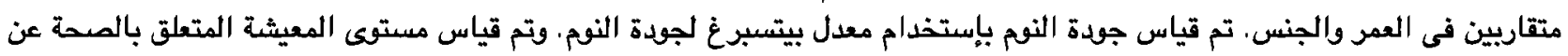
طريق "إستيان القديس جدرج التنفسي" وقد تم تقييم وجود القلق بإستخدام مقياس "هاميلتون" وتقييم الإكتئاب بإستخدام "مقياس بيك للإكتئاب".

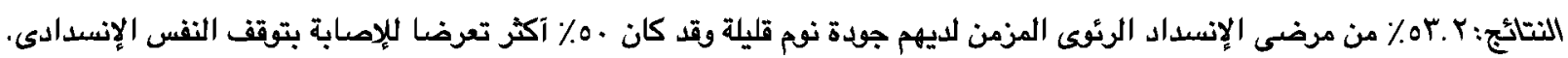

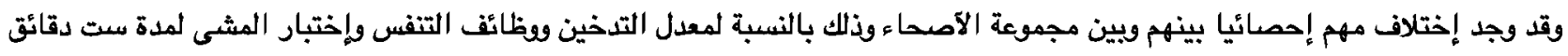
وإستبيان برلين ومعدل بيتسبرغ لجودة النوم وإستبيان إيبوندس اللنوم ومقياس "هاميلتون ومقياس بيك للإكتئاب".

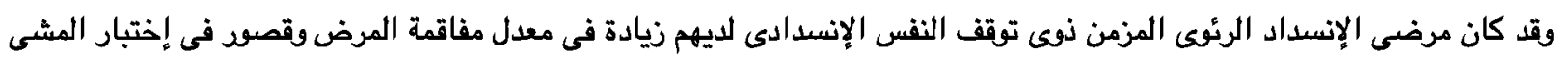

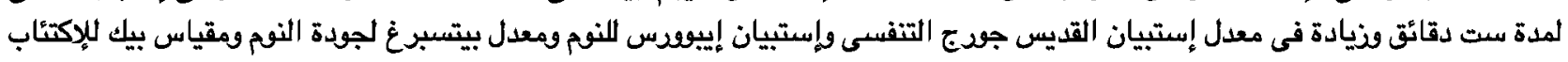

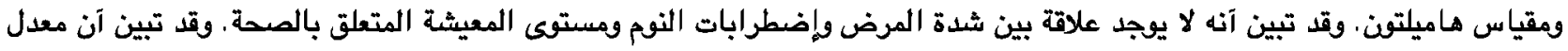

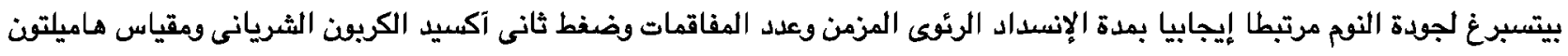

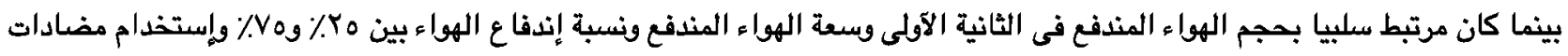

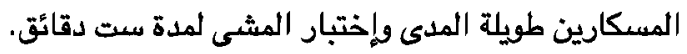

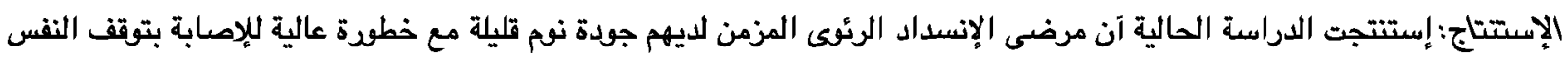

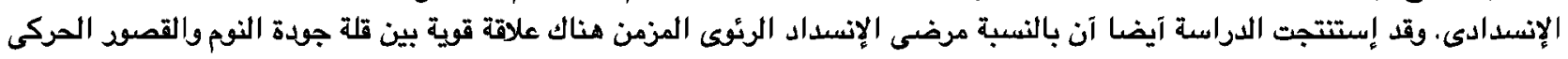
والقلق والإكتئاب ومستوى المعيشة المتعلق بالصحة. 